\title{
Aplicação de esterco bovino e uréia na couve e seus reflexos nos teores de nitrato e na qualidade.
}

\author{
Valéria Cristina P. Zago ${ }^{1}$; Marcus R. Evangelista; Dejair L. de Almeida; José Guilherme M. Guerra; \\ Maria Cristina P. Neves; Norma G. Rumjanek. \\ Embrapa Agrobiologia, C. Postal 74505, 23.851-970 Seropédica-RJ.e-mail: agrob@cnps.embrapa.br
}

\section{RESUMO}

O excesso de nitrato nos alimentos é indesejável devido à sua conversão a nitrito, composto conhecido por participar de reações formadoras de compostos cancerígenos e modificadores da hemoglobina. A influência da aplicação de esterco bovino, uréia e a associação destes nos teores de $\mathrm{N}_{-} \mathrm{NO}_{3}{ }^{-}$presente nos tecidos foliares de couve (Brassica oleracea var. acephala) foi avaliada, com o objetivo de verificar o efeito de fontes e doses diferentes de nitrogênio no acúmulo deste composto. Para tanto, um experimento foi conduzido a campo, de março a agosto de 1995, na Embrapa Agrobiologia. $\mathrm{O}$ delineamento experimental adotado foi o de blocos ao acaso, com quatro repetições e seis tratamentos: adubação com esterco bovino (20 t/ha), aplicação de N-uréia (900 kg/ha), associação de esterco (20 t/ha) com doses crescentes de N-uréia (225; 450 e $900 \mathrm{~kg} / \mathrm{ha})$ e testemunha. O espaçamento foi de $0,6 \mathrm{~m}$ entre plantas, $0,6 \mathrm{~m}$ entre linhas e $0,8 \mathrm{~m}$ entre fileiras duplas, perfazendo um total de 24 parcelas com $9,6 \mathrm{~m}^{2}$ cada. Verificou-se que as plantas adubadas exclusivamente com esterco apresentaram nos limbos foliares, menores conteúdos de nitrato que aquelas que receberam uréia complementar (17,6 mg/g M.F. e 303 a 579 mg/g M.F.), respectivamente. Enquan-

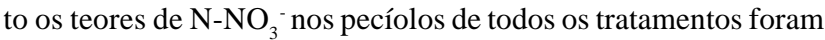
pelo menos três vezes maiores que os observados nos limbos foliares (1.830 e $561 \mathrm{mg} / \mathrm{g}$ M.F.), respectivamente. A OMS recomenda uma dose diária aceitável (DDA) de 53,3 $\mathrm{mg}$ de $\mathrm{N}^{-\mathrm{NO}_{3}}$, para um adulto de $65 \mathrm{~kg}$, isto é, a quantidade máxima deste composto que pode ser ingerida diariamente, através dos alimentos e da água. Considerando-se os dados obtidos no experimento, seria necessário o consumo de 2,67 kg de couve (limbos foliares) quando produzida apenas com esterco (20 t/ha) e $0,18 \mathrm{~kg}$ quando adubadas com esterco (20 t/ha) + $111 \mathrm{~kg} / \mathrm{ha}$ de uréia (próximo a dosagem recomendada pelo Manual de Adubação do Rio de Janeiro), para atingir a DDA. Devido aos menores teores de nitrato encontrados na couve adubada exclusivamente com esterco, conclui-se que este adubo proporcionou um produto de melhor qualidade para consumo.

Palavras-chave: Brassica oleracea var. acephala, nitrogênio, matéria orgânica, compostos cancerígenos .

\section{ABSTRACT}

Cattle manure and urea use on kale and their influence on the quality and nitrate content.

High levels of nitrate in food is undesirable, as it may be easily converted to nitrite, which is a well known carcinogenic compound that can also interfere with hemoglobin activity. The objective of this study was to evaluate the influence of different forms of $\mathrm{N}$-fertilizer (cattle manure, urea and a mixture of both) on the $\mathrm{N}_{-} \mathrm{NO}_{3}{ }^{-}$concentration observed on leaf tissues of kale (Brassica oleracea var. acephala). A field experiment was conducted from March until August 1995, at the Embrapa-Agrobiology Research Center. The experiment was laid out in a randomized block design, with six treatments: cattle manure addition (20 t/ha), urea addition $(900 \mathrm{~kg} / \mathrm{ha})$, mixtures of cattle manure (20 t/ha) with increasing urea levels $(225,450$ and $900 \mathrm{~kg} / \mathrm{ha})$ and a control. A total of four replicates was used. The distance between plants in a row and between single rows was $0.6 \mathrm{~m}$, and $0.8 \mathrm{~m}$ was the distance between double rows. A total of 24 plots with $9.6 \mathrm{~m}^{2}$ each was used. Plants growing solely on cattle manure showed lower nitrate contents on leaf blades than those receiving additional urea $(17.6 \mathrm{mg} /$ g F. M. and $303 \mathrm{mg} / \mathrm{g} \mathrm{F}$. M.), respectively. Petiole $\mathrm{N}^{-\mathrm{NO}_{3}}{ }_{3}$ contents for all treatments were three times higher than the ones observed in leaf blades (1830 and $561 \mathrm{mg} / \mathrm{g} \mathrm{F}$. M.), respectively. According to WHO, the Daily Acceptable Intake (DAI) for an adult weighting $65 \mathrm{~kg}$ is $53.3 \mathrm{mg}$ of $\mathrm{N}^{-\mathrm{NO}_{3}}$, which represents the maximum quantity this compound that can be swallowed daily, through food and water. From the results obtained, the DAI would be reached after consumption of $2.67 \mathrm{~kg}$ of kale (leaf blade) cultivated under cattle manure fertilization, or just $0.18 \mathrm{~kg}$ of kale cultivated under cattle manure and urea (111 $\mathrm{kg} / \mathrm{ha}$ ) fertilization, which approximates to the urea dosage recommended in the "Manual de Adubação de Rio de Janeiro". As a result of the lower nitrate contents found in kale growing solely on cattle manure, it was concluded that the cattle manure fertilization improved the quality of the product.

Keywords: Brassica oleracea var. acephala, nitrogen, organic matter, carcinogenic compound.

(Aceito para publicação em 20 de agosto de 1999)

\begin{abstract}
A atenção mundial das ciências agrícola e nutricional tem focalizado atualmente, a controvérsia concernente à qualidade versus quantidade dos alimentos produzidos, e que juntamente com os problemas ambientais emergentes, que
\end{abstract}

decorrem da utilização dos recursos naturais de forma predatória, têm conduzido a pesquisa agrícola à busca de alternativas que possam substituir o uso de insumos agrícolas-industriais, de elevados custos energéticos, econômicos e sociais.
A utilização de fertilizantes é um dos vários fatores que pode influenciar a composição química dos vegetais e, consequentemente, sua qualidade biológica. Diversos estudos têm comprovado que o uso excessivo de fertilizantes

\footnotetext{
${ }^{1}$ Endereço atual: Embrapa-Agrobiologia, C.Postal 74505, 23851-970Seropédica-RJ.
} 
nitrogenados aumenta o acúmulo de nitrato nos vegetais (Pereira et al., 1989; Rodrigues, 1990; Almeida, 1991; Ricci,1993). Tal problemática tem recebido especial atenção em alguns países, visto que, o excesso de nitrato na dieta, com sua posterior conversão a nitrito, pode conduzir a formação de compostos cancerígenos e, indiretamente, inibir o transporte de oxigênio no sangue, alteração metabólica conhecida como metahemoglobinemia. Recém-nascidos formam o principal grupo de risco devido a baixa acidez estomacal deste, levando a uma rápida conversão do nitrato a nitrito.

Uma estimativa da ingestão média de nitrato revelou que para um consumidor normal, os vegetais representam um quarto do total de nitrato ingerido (Walker, 1975). Também para Reinink \& Blom-Zandstra (1989); Laitinen et al., (1993) e Meach et al., (1994), a principal fonte de nitrato na alimentação humana origina-se da ingestão de olerícolas.

A exigência de alta disponibilidade de nitrogênio pelas hortaliças é uma das condições responsável pela utilização de altas doses de fertilizantes nitrogenados ao longo do ciclo de cultivo. $\mathrm{O}$ presente trabalho teve como objetivo a avaliação dos efeitos da aplicação de uréia, esterco e suas associações, nos teores de N$\mathrm{NO}_{3}{ }^{-}$nas folhas de couve.

\section{MATERIAL E MÉTODOS}

O experimento foi conduzido no campo experimental da Embrapa agrobiologia, Seropédica-RJ, num Planossolo, com as seguintes características químicas: $\mathrm{pH}$ em água $(1: 2,5)=$ 4,7; Al trocável = $3 \mathrm{mmol}_{\mathrm{c}} / \mathrm{dm}^{3} ; \mathrm{Ca}+$ Mg trocável $=15 \mathrm{mmol}_{\mathrm{c}} / \mathrm{dm}^{3} ; 34 \mathrm{mg} /$ $\mathrm{dm}^{3}$ de P extraível; $22 \mathrm{mg} / \mathrm{dm}^{3}$ de K extraível; 3 g/kg de C; 5,2 g/kg de M.O. (Embrapa, 1979); 0,4 g/kg de $\mathrm{N}$ (Bremmer \& Mulvaney, 1982).

O preparo inicial do solo constou de aração e gradagem, com aplicação de $750 \mathrm{~kg} / \mathrm{ha}$ de calcário dolomítico (PRNT $=80 \%$ ), com teores de $38 \%$ de $\mathrm{CaO}$ e $10 \%$ de $\mathrm{MgO}$, um mês anterior ao plantio definitivo no campo. A área experimental era coberta, anteriormente, com vegetação espontânea, predominante- mente de Indigofora hirsuta, leguminosa herbácea, incorporada ao solo durante a aração.

O delineamento experimental adotado foi o de blocos ao acaso, com quatro repetições e seis tratamentos: testemunha (sem esterco e sem uréia); adubação orgânica (20 t/ha de esterco bovino); adubação orgânica + uréia na dose 1 (20 t/ha de esterco $+225 \mathrm{~kg} / \mathrm{ha}$ de Nuréia); adubação orgânica + uréia na dose 2 (20 t/ha de esterco $+450 \mathrm{~kg} / \mathrm{ha}$ de N-uréia); adubação orgânica + uréia na dose 3 (20 t/ha de esterco $+900 \mathrm{~kg} /$ ha de N-uréia) e uréia na dose-3 (900 $\mathrm{kg} / \mathrm{ha}$ de $\mathrm{N}$-uréia).

As mudas foram formadas a partir de sementes de couve, do grupo Geórgia, em canteiro adubado com esterco bovino curtido e, transplantadas para o local definitivo um mês após a semeadura. O espaçamento foi de 0,6 $\mathrm{m}$ entre plantas, $0,6 \mathrm{~m}$ entre linhas e 0,8 $\mathrm{m}$ entre fileiras duplas, perfazendo um total de 24 parcelas com 9,6 $\mathrm{m}^{2}$ cada.

A aplicação de uréia foi parcelada e aplicada em cobertura, quinzenalmente, até o final do experimento, sendo a aplicação inicial 15 dias após o transplantio das mudas para o campo. $\mathrm{O}$ esterco foi aplicado em uma única dosagem e incorporado na cova de plantio, juntamente com $100 \mathrm{~kg}$ de $\mathrm{K}_{2} \mathrm{O} / \mathrm{ha}$, na forma de $\mathrm{KCl}$. A análise química do esterco apresentou os seguintes teores de nutrientes $(\mathrm{g} / \mathrm{kg}$ de matéria seca): $\mathrm{N}=9,29 ; \mathrm{P}=2,67 ; \mathrm{K}=8,25 ; \mathrm{Ca}=3,84$; $\mathrm{Mg}=3,08 ; \mathrm{Cu}=0,01 ; \mathrm{Zn}=0,7 ; \mathrm{B}=0,02 ;$ $\mathrm{Fe}=1,77 ; \mathrm{Mo}=<0,1 ; \mathrm{Mn}=0,31 ; \mathrm{M} . \mathrm{O} .=$ 152,8; $\mathrm{C}=84,7$ com umidade $\left(65^{\circ}\right.$ $\mathrm{C})=39,11 \%$ e pH em água $(1: 2,5)=6,8$. A irrigação foi do tipo aspersão convencional, com turno de rega médio diário, sendo o controle da lâmina feito através do tempo de irrigação. A condução do experimento se deu em período de baixa precipitação.

Realizaram-se três amostragens no período inicial de produção de folhas de couve, sendo estas: um, cinco e quinze dias após a segunda adubação em cobertura com uréia (30 dias após o transplantio), onde os tratamentos receberam, até aquele momento, as quantidades equivalentes a $50 \mathrm{~kg} / \mathrm{ha}$ (dose 1 ), $100 \mathrm{~kg} / \mathrm{ha}$ (dose 2) e $200 \mathrm{~kg} / \mathrm{ha}$ (dose 3) de uréia.
Foram amostradas duas folhas inferiores completamente desenvolvidas, das quatro plantas centrais da parcela. Estas foram separadas em "limbo foliar" e "pecíolo + nervura central". Após homogeneização deles, retirou-se uma amostra de cinco gramas do material fresco ("limbo foliar" e "pecíolo + nervura central”), para extração alcoólica (Magalhães et al., 1992), onde procedeu-se à separação da fração polar (metanólica) para retenção dos compostos solúveis, fração apolar (cloroformio) e resíduo do tecido foliar. A partir do extrato metanólico obtido determinou-

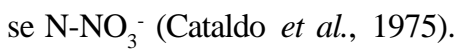

Os procedimentos estatísticos constaram de análises de variância pelo teste F. Nas fontes de variação, onde houve diferença significativa, aplicou-se o teste de Tukey a 5\%, para comparação de médias.

A análise de variância, para as três coletas, foi feita em esquema "splitplot", sendo os seis tratamentos na parcela e as coletas na subparcela. Visando isolar alguns efeitos, os cinco graus de liberdade relativos ao efeito de tratamento foram desdobrados nos seguintes contrastes ortogonais: a testemunha contra os outros tratamentos que receberam alguma fonte de nitrogênio (1 grau de liberdade); os tratamentos que receberam esterco contra aquele que recebeu somente uréia (1 grau de liberdade); análise de regressão (termos linear, quadrático e cúbico) dos tratamentos que receberam esterco + doses crescentes de uréia (três graus de liberdade) (Tabela 3).

\section{RESULTADOS E DISCUSSÃO}

As plantas que receberam apenas esterco bovino (trat. 2) apresentaram nos limbos foliares e nos pecíolos + nervura central, teores de $\mathrm{N}-\mathrm{NO}_{3}{ }^{-}$similares aos das plantas testemunhas (Tabelas 1 e 2).

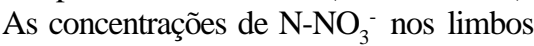
foliares mostraram interação entre as amostragens. De modo geral, os tratamentos apresentaram concentrações mais altas de $\mathrm{N}_{-} \mathrm{NO}_{3}^{-}$no quinto dia após a aplicação da uréia, observando-se a partir daí uma diminuição neste parâmetro, com exceção do tratamento 5 , onde os teores de $\mathrm{N}^{-\mathrm{NO}_{3}^{-}}$aumenta- 
ram a partir do quinto dia após a aplicação de uréia e o tratamento 6 , que recebeu somente aplicação de uréia, sendo que os teores de $\mathrm{N}^{-\mathrm{NO}_{3}}{ }^{-}$foram maiores no primeiro dia, caindo no quinto e voltando a subir no décimo quinto dia após a aplicação de uréia (Tabela 1).

Após o primeiro dia da aplicação, o teor de $\mathrm{N}_{-} \mathrm{NO}_{3}^{-}$observado nas plantas que receberam adubação complementar com uréia, na dose próxima à recomendada para a cultura $(50 \mathrm{~kg} / \mathrm{ha}$ de $\mathrm{N}$-uréia) pelo Manual de Adubação do Estado do Rio de Janeiro (Almeida et al., 1988), foi cerca de 50 vezes maior do que aquele observado para o tratamento que recebeu apenas esterco, observando-se um declínio nesta taxa ao longo do período para cerca de 8 vezes (Tabela 1).

Os dados referentes aos teores $\mathrm{N}$ $\mathrm{NO}_{3}{ }^{-}$nos pecíolos não mostraram interação, sendo que o tratamento com esterco foi inferior aos tratamentos que receberam adubação complementar com uréia, não diferindo, no entanto, daquele que recebeu exclusivamente uréia (Tabela 2). Outros trabalhos também relatam teores de nitrato maiores em plantas adubadas com adubos industriais em relação a adubos orgânicos em diferentes olerícolas: cenoura (Lecterc, 1987); alface (Pereira et al., 1989; Rodrigues, 1990; Almeida, 1991; Ricci, 1993); cenouras, alho-poró e vagem (Bosh et al., 1991); alface, rabanete, repolho, beterraba, cenoura, salsa, aipo e batata (Rutkowska, 1993). Enquanto Silva (1985) e Lyons et al. (1994) não observaram diferenças significativas quanto aos teores de nitrato para vegetais produzidos com esterco adubos minerais.

Pôde-se observar também que, apesar das quantidades de nitrogênio presentes no tratamento que recebeu exclusivamente esterco (equivalente a $186 \mathrm{~kg}$ de N/ha, trat. 2) e naquele onde a adubação foi apenas com uréia (equivalente a $200 \mathrm{~kg}$ de N/ha, trat.6) terem sido próxi-

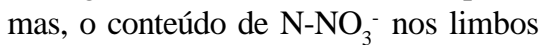
foliares das plantas com uréia, no primeiro dia após a aplicação de uréia, foi cerca de 80 vezes maior do que as plantas que receberam apenas esterco, observando-se um declínio nesta taxa ao longo do período (Tabela 1). Isto parece ser em parte, devido ao nitrogênio do esterco tornar-se disponível às plantas de forma

Tabela 1. Teores de $\mathrm{N}-\mathrm{NO}_{3}{ }^{-}$nos limbos foliares ( $\mathrm{mg} \mathrm{N} \cdot \mathrm{g}^{-1}$ matéria fresca), como resposta à adubação com esterco bovino e/ou doses crescentes de uréia, valores das folhas coletadas aos um, cinco e quinze dias após a segunda adubação de cobertura com uréia. Seropédica (RJ), Embrapa Agrobiologia, 1995.

\begin{tabular}{|c|c|c|c|c|}
\hline Tratamentos & 10 dia & 5o dia & 150 dia & médias \\
\hline 1-Testemunha & $2,1^{5} \mathrm{Ba}$ & $27,5 \mathrm{Ba}$ & $19,2 \mathrm{Ba}$ & $16,3 \mathrm{~B}$ \\
\hline 2-Esterco ${ }^{1}$ & $7,5 \mathrm{Ba}$ & $27,3 \mathrm{Ba}$ & $17,9 \mathrm{Ba}$ & $17,6 \mathrm{~B}$ \\
\hline 3-Esterco+ uréia na dose $1^{2}$ & $357 \mathrm{ABa}$ & $404 \mathrm{ABa}$ & $148 \mathrm{Ba}$ & $303 A B$ \\
\hline 4-Esterco + uréia na dose $2^{3}$ & $186 \mathrm{ABb}$ & $669 \mathrm{Aa}$ & $409 \mathrm{ABab}$ & $421 \mathrm{~A}$ \\
\hline 5 -Esterco + uréia na dose $3^{4}$ & $455 \mathrm{ABa}$ & $613 \mathrm{Aa}$ & $668 \mathrm{Aa}$ & $579 \mathrm{~A}$ \\
\hline 6-Uréia na dose $3^{4}$ & $649 \mathrm{Aa}$ & $355 \mathrm{ABa}$ & $678 \mathrm{Aa}$ & $561 \mathrm{~A}$ \\
\hline Médias & $276 a$ & 349 a & $323 a$ & \\
\hline
\end{tabular}

${ }^{1}$ esterco $=20 \mathrm{t} / \mathrm{ha}$;

${ }^{2,3,4}$ uréia $1=50 \mathrm{~kg} \cdot \mathrm{ha}^{-1}$; uréia $2=100 \mathrm{~kg} \cdot$ ha $^{-1}$; uréia $3=200 \mathrm{~kg} \cdot \mathrm{ha}^{-1}$;

${ }^{5}$ valores seguidos de letras iguais, minúsculas nas linhas e maiúsculas nas colunas não diferem significativamente entre si pelo teste de Tukey $(\mathrm{p}<0,05)$.

Tabela 2. Teores de $\mathrm{N}-\mathrm{NO}_{3}{ }_{3}^{-}$nos pecíolos + nervuras ( $\mathrm{mg} \mathrm{N} \mathrm{g}^{-1}$ matéria fresca), como resposta à adubação com esterco bovino e/ou doses crescentes de uréia, valores das folhas coletadas aos um, cinco e quinze dias após a segunda adubação de cobertura com uréia. Seropédica (RJ), Embrapa Agrobiologia, 1995.

\begin{tabular}{lllll}
\hline \multicolumn{1}{c}{ Tratamentos } & \multicolumn{1}{c}{ 10 dia } & 50 dia & 150 dia & médias \\
\hline 1-Testemunha & 3495 & 967 & 774 & $697 \mathrm{C}$ \\
2-Esterco $^{1}$ & 359 & 886 & 777 & $873 \mathrm{BC}$ \\
3-Esterco + uréia na dose 12 $^{2}$ & 2328 & 2129 & 1618 & $2025 \mathrm{~A}$ \\
4-Esterco + uréia na dose 2 & 1789 & 2678 & 1664 & $2044 \mathrm{~A}$ \\
5-Esterco + uréia na dose 34 & 2578 & 2185 & 2570 & $2444 \mathrm{~A}$ \\
6-Uréia na dose 34 & 1537 & 2259 & 1693 & $1830 \mathrm{AB}$ \\
Médias $^{4}$ & $1490 \mathrm{a}$ & $1851 \mathrm{a}$ & $1515 \mathrm{a}$ & \\
\hline
\end{tabular}

${ }^{1}$ esterco $=20$ t/ha;

${ }^{2,3,4}$ uréia $1=50 \mathrm{~kg} \cdot \mathrm{ha}^{-1} ;$ uréia $2=100 \mathrm{~kg} \cdot \mathrm{ha}^{-1} ;$ uréia $3=200 \mathrm{~kg} \cdot \mathrm{ha}^{-1}$;

${ }^{5}$ valores seguidos de letras iguais, minúsculas nas linhas e maiúsculas nas colunas não diferem significativamente entre si pelo teste de Tukey $(\mathrm{p}<0,05)$.

mais gradual (Rodrigues, 1990; Kiehl, 1993). Além disso, é possível que outros nutrientes presentes no esterco, também possam ter importante papel no metabolismo de acúmulo de nitrogênio, na forma de nitrato.

O potássio, por exemplo, participa da ativação das enzimas assimilatórias de amônia e transporte de aminoácidos. Altos níveis de potássio resultam em aumentos na taxa de transferência de compostos nitrogenados solúveis para frações insolúveis devido ao efeito deste nutriente na síntese de proteínas (Hagin et al., 1990). Nas plantas adubadas exclusivamente com esterco, os teores de potássio foram maiores (41 e $75 \mathrm{~g} / \mathrm{kg}$ ), nos limbos foliares e nos pecíolos, quando comparadas àquelas que receberam além de esterco, adubação complementar com uréia em doses crescentes ou apenas uréia, que apresentaram valores variando de 22 a 35 e 48 a 66 g/kg, nos limbos e pecíolos, respectivamente.

Outro elemento importante na assimilação do nitrogênio é o Mo, visto ser este micronutriente um componente essencial da nitrato redutase que favorece 
a redução nos teores de nitrato dos tecidos vegetais (Mondy \& Munshi, 1993; Pansenhagen et al., 1996).

De acordo com a Organização Mundial de Saúde da FAO, a Dose Diária Aceitável (DDA) para nitrato é de no máximo $325 \mathrm{mg}$ de $\mathrm{NaNO}_{3}$, que corresponde a $53,5 \mathrm{mg}$ de $\mathrm{N}_{-} \mathrm{NO}_{3}^{-}$, por dia, para um adulto de $65 \mathrm{~kg}$ de peso (Olmedo \& Bosh,1988). Para atingir os valores recomendados pela OMS e, usando os dados médios da concentra-

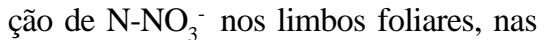
amostragens realizadas $(0,02 \mathrm{mg}$ de $\mathrm{N} /$ g M.F., trat.2 e 0,3 mg de N/g M.F., trat.3), no período inicial de produção de folhas, calculou-se as quantidades de couve que teriam que ser consumidas para atingir $100 \%$ da DDA. Desta forma, chegou-se as quantidades de 2,70 $\mathrm{kg}$ de couve, quando esta foi produzida apenas com esterco e $0,20 \mathrm{~kg}$, quando as plantas foram crescidas suplementadas com esterco $+50 \mathrm{~kg} / \mathrm{ha}$ de $\mathrm{N}$-uréia (dose próxima à recomendada para a cultura, pelo Manual de Adubação do Rio de Janeiro (Almeida et al., 1988). Estes valores foram calculados sem considerar os teores contidos nos pecíolos, que elevariam muito a concentração de $\mathrm{N}^{-} \mathrm{NO}_{3}^{-}$, principalmente nos tratamentos que receberam uréia (Tabela 2). Se acrescentássemos os teores de $\mathrm{N}_{-} \mathrm{NO}_{3}{ }^{-}$presente nos pecíolos, a DDA estaria contida em apenas $0,06 \mathrm{~kg}$ de couve adubada com apenas esterco e $0,02 \mathrm{~kg}$ de couve adubada com esterco $+50 \mathrm{~kg} / \mathrm{ha}$ de $\mathrm{N}$-uréia.

Considerando-se que um adulto consuma em média uma porção de 60 gramas de couve fresca ou cozida (limbos foliares), estaria ingerindo $1,2 \mathrm{mg}$ de $\mathrm{N}$ $\mathrm{NO}_{3}{ }^{-}$de couve produzida apenas com esterco e, aproximadamente $18 \mathrm{mg}$ de $\mathrm{N}^{-\mathrm{NO}_{3}}{ }^{-}$quando as plantas forem adubadas com uréia, numa quantidade aproximada àquela recomendada pelo Manual de Adubação do Rio de Janeiro (Almeida et al., 1988). Porém, o consumo comum de couve envolve as nervuras centrais que foram, neste experimento, analisadas juntamente com os pecíolos, desta forma, os valores acima estão subestimados. Levando-se em conta os altos teores de nitrato encontrados nos pecíolos de couve, é recomendável a retirada destes, no momen- to da preparação dos alimentos, principalmente em se tratando do consumo infantil, como forma de evitar os efeitos tóxicos.

Estes resultados são importantes, visto o perigo que o nitrato oferece à saúde humana, pela transformação deste em nitrito durante o armazenamento das hortaliças, seu preparo e por ação da saliva e do estômago, devido à ação de microrganismos (Ahrens, 1983). O nitrito tem a propriedade de formar nitrosaminas, que são substâncias comprovadamente carcinogênicas. Em crianças recém - nascidas, o nitrito pode levar à chamada cianose, isto é, uma deficiência na absorção de oxigênio pelo sangue (Vogtmann \& Wagner, 1987).

A preocupação com a concentração de nitrato e nitrito em vegetais tem levado alguns países europeus a fixarem limites máximos aceitáveis. A Yusgoslavia, por exemplo, estabelece o máximo de 50 ppm de $\mathrm{KNO}_{3}$ para alimentos infantis preparados com vegetais, enquanto na Suíça admite-se o valor máximo de 4,0 $\mathrm{g}$ de $\mathrm{NO}_{3}^{-} / \mathrm{kg}$ para alface. Já na Holanda, para culturas de inverno e verão, os máximos estabelecidos são de 4,5 e 2,5 $\mathrm{g}$ de $\mathrm{NO}_{3}^{-} / \mathrm{kg}$ de matéria fresca, respectivamente (Olmedo \& Bosch, 1988; Gunes et al., 1996). No entanto, no Brasil não existe legislação específica que regulamente os teores máximos permissíveis de nitrato e nitrito em alimentos vegetais.

Dentro do contexto sócio-econômico agrícola do Estado do Rio de Janeiro, com $80 \%$ da população rural formada por pequenos agricultores, em sua maioria de baixa renda e visando um mercado em expansão, em busca de produtos com melhor qualidade biológica, a utilização de recursos disponíveis dentro da propriedade, como o uso de estercos animais, pode ser uma alternativa a mais para uma maior independência do produtor e oferta de alimentos mais saudáveis.

\section{AGRADECIMENTOS}

Aos pesquisadores Marco Antônio Leal e Marcelo Grandi Teixeira, pelo auxílio nas análises estatísticas e a Rojane Chapeta Peixoto pelo apoio técnico.

\section{LITERATURA CITADA}

ALMEIDA, D.L. Contribuições da adubação Orgânica para a fertilidade do solo. UFRRJ, Itaguaí-RJ, 1991, 188 p. (Tese doutorado).

ALMEIDA, D.L.; SANTOS, G.A.; DE-POLLI, H.; CUNHA, L.H.; FREIRE, L.R.; AMARAL SOBRINHO, N.M.B.; PEREIRA, N,N,C.; EIRA, P.A.; BLOISE, R.M.; SALEK, R.C. Manual de Adubação para o Estado do Rio de Janeiro, 1988. 179 p. (Coleção Universidade Federal Rural. Ciências Agrárias, 2).

AHRENS, E. Significance of fertilization for postharvest condition of vegetables, especially spinash. In: Environmentally sound agriculture. New York, Praeger Publishers, p. 229-246, 1983.

BREMMER, J.M.; MULVANEY, C.S. Nitrogen Total. In: Methods of Soil Analysis Part 2 Chemical and Microbiological Properties Monograpf. v. 9, n. 2, p. 595-624, 1982.

BOSH, N.; MARTINEZ ALVAREZ, J.R.; PEREZ RODRIGUES, M.L. Effect of fertilizer type on nitrate accumulation in vegetables. Anales de Bromatologia v. 43, n. 2/3, p. 215-220, 1991.

CATALDO, D.A; HAROON, M.; SCHRADER, L.; YOUNGS, V.L. Rapid colorimetric determination of nitrate in plant tissue by nitration of salicylic acid. Communications of Soil and Science Plant Anal., v. 6, n. 1, p. 7180, 1975.

EMBRAPA. Serviço Nacional de Levantamento e Conservação do Solo. Rio de Janeiro. Manual de Métodos de Análises do Solo. Rio de Janeiro, 1979. 1 v. il.

GUNES, A; INAL, A.; AKTAS, M. Reducting nitrate content of NFT grown winter onion plants (Allium cepa L.) by partial replacement of $\mathrm{NO}_{3}$ with amino acid in nutrient solution. Scientia Horticulturae, v. 65, p. 203-208, 1996.

HAGIN, J.; OLSEN, S.; SHAVIO, A. Review of interaction of ammonium-nitrate and potassium nutrition of crops. Journal of Plant Nutrition, v. 13, n. 10, p. 1211-1226, 1990.

KIEHL, E.J. Fertilizantes Organominerais. Piracicaba - SP, 1993, 189 p.

LAITINEN, S.; VIRTANEN, S.M.; RASANEN, L.; PENTTILA, P.L. Calculated dietary intakes of nitrate and nitrite by young Finns. Food Addition Contamination, v. 10, n. 4, p. 469477, 1993.

LECTERC, B. Mineralization of nitrogen of organic fertilizers and nitrate contents in carrots cultivated in spring. In: Conservation y elaboration de alimentos, p. 272-278, 1993.

LYONS, D.J.; RAYMENT, G.E.; NOBBS, P.E.; MACCALLUM, L.E. Nitrate and nitrite in fresh vegetables from Queesland. Journal the Science of Food and Agriculture, v. 64, n. 3, p. 279-281, 1994.

MAGALHÃES, J.R.; HUBER, D.M.; TSAI, C.Y. Evidence of increased $\mathrm{N}$-ammonium assimilation in tomato plants with exogenous alfa-ketoglutarate. Plant Science, v. 85, p. 135141, 1992.

MEACH, M.N.; HARRISON, N.; DAVIS, A. Nitrate and nitrite in foods and the diet . Food Addition Contamination., v. 11, n. 4, p. 519532, 1994. 
MONDY, N.I.; Munshi, C.B. Effect of soil and foliar application of molybdenum on the glycoalkaloid and nitrate concentration of potatoes. Journal the Agriculture and Food Chemical, v. 41, p. 256-258, 1993.

OLMEDO, R.G.; BOSH, N.B. Ingestion de nitratos procedentes de productos hortícolas, y su incidencia toxicológica. Alimentaria, v. 25, p. 76-78, 1988

PANSENHAGEN, N.V., SCHWARZ, R.; CLARO, S.A. Produção e qualidade de alface (Lactuca sativa L.) em função de fontes de doses de nitrogênio. In: XXXVI Congresso Brasileiro de Olericultura, Rio de Janeiro-RJ, Anais... p.105, 1996. (Resumo expandido).

PEREIRA, N.; FERNANDES, M.S.; ALMEIDA, D.L. Adubação nitrogenada na cultura da alface: Fontes de $\mathrm{N}$ e inibidor de nitrificação. Pesquisa Agropecuária Brasileira, Brasília, v.4, n. 6, p. 647-654, 1989.
REININK, K.; BLOM-ZANSTRA, M. The relation between cell size, ploidy level and nitrate concentration in lettuce. Physiology Plantarum, v. 76, p. 575-580, 1989.

RICCI, M.S.F. Crescimento e teores de nutrientes em cultivares de alface (Lactuca sativa $L$ ) adubados com vermicomposto. Viçosa: UFV, 1993. 101 p. (Tese doutorado).

RODRIGUES, E.T. Efeitos das adubações orgânicas e mineral sobre o acúmulo de nutrientes e sobre o crescimento da alface (Lactuca sativa L. ). Viçosa- MG: Universidade Federal de Viçosa, 1990. 60 p. (Tese mestrado).

RUTKOWSKA, G. Contents of nitrites and nitrates in vegetables. Chlodnictwo, v. 28, n. 2, p. 29-31, 1993.
SILVA, JJ.S. Adubação orgânica e inorgânica e suas relações com a qualidade nutritiva e com o rendimento de grãos de feijão e ervilha. UFRGS, Porto Alegre, RS, 1985. (Tese mestrado).

VOGTMANN, H.; WAGNER, R. Agricultura ecológica: Teoria e prática. Porto Alegre, RS, Mercado Aberto, 1987. 168 p.

WALKER, R. Naturally ocurring nitrate/nitrite in foods. Journal of Science and Food Agriculture, v. 26, p. 1735-1742, 1975. 